\title{
CROSS-DOMAIN \\ COLLABORATIVE LEARNING AND THE TRANSFORMATION OF FACULTY IDENTITY
}

James B. Young

This chapter addresses how faculty from disparate backgrounds collaborate in interdisciplinary learning communities and how this cross-domain collaboration leads to a tangible change in identity. Faculty enter learning communities playing the more common roles of expert and teacher, but they leave taking on the additional roles of novice, learner, and knowledge integrator. The experience of cross-domain interaction is both rewarding and transformative for faculty as they are well equipped to communicate across the disciplinary landscape and gain a rhetorical awareness that is an invaluable ingredient for learning community participation.

Faculty play multiple, simultaneous roles in interdisciplinary learning communities in the Anonymous College $(\mathrm{AC})$ integrative studies program at Large State University. They assume the expected roles of expert and teacher in collaboration with other faculty from across the disciplinary landscape on diverse cross-domain projects such as course design, instruction, and assessment in both the general education and upper-division curriculum in integrative studies. Within collaborative circles of two to eight instructors, faculty take on the additional, and often new, roles of novice, learner, and knowledge integrator. The creative tension that results from cross-domain interaction is both a rewarding and transformative experience for individuals, faculty teams, and the students who have ready access to faculty who do much more than teach; they model collaborative learning as context-sensitive experts. 


\section{How Faculty Typically Interact}

Faculty are knowledge workers with deep expertise in a particular field. As part of their day-to-day work, they interact regularly with colleagues both within and outside their departments and, as part of their academic responsibilities, with peers from other institutions who share their intellectual pursuits or associational interest. Faculty collaboration is common, but the interactions within these collaborations are almost always framed in a sociocultural domain of like-minded experts protective of discipline-specific boundaries. Discipline-driven curricula, increased specialization, traditional rewards and motivations, and university organizational structures that resist change all help form and reinforce this prevailing culture of faculty interaction.

Most faculty collaboration, and therefore most faculty learning, occurs in the field in which they have been trained to be experts. As most universities and colleges organize their programs into departments by discipline or field, faculty typically interact with faculty of similar discipline, intellectual training, and professional background. For the most part, faculty members are not socialized, encouraged, or rewarded for cross-domain collaboration. Faculty ways of knowing, fostered in graduate study and individual scholarly pursuit, are increasingly governed by pressure to specialize. They have little choice but to become more conversant in areas they already know a great deal about. The dearth of opportunities or motivations for bridging chasms promoted by this pervasive culture of expertise hinders faculty opportunities to collaborate on cross-domain teaching and learning and therefore blunts chances to learn from each other across boundaries. One way to chip away at this prevailing university culture is for faculty to collaborate in learning communities.

\section{Literature Review}

It is relatively rare, in the literature and in practice, for faculty from diverse areas of expertise to work in intense, interdisciplinary work teams or crossfunctional groups (Cox, 2004; Creamer, 2005). There are, however, multiple, broader frameworks in the higher education literature in which to place learning communities (Becher \& Trowler, 2001; Smith, Macgregor, Matthews, \& Gabelnick, 2004; Tagg, 2003; Tierney, 2008). The literature on communities of practice comes from the fields of knowledge management and organizational learning (Berthoin Antal, Lenhardt, \& Rosenbrock, 2001; Davenport \& Prusak, 1998; Dixon, 2000; Nonaka, 2008; Wenger, 1998; Wenger, McDermott, \& Snyder, 2002). The common thread in the learning community and community of practice literature is that learning 
is social, dynamic, and rooted in the exchange of knowledge across organizational or disciplinary boundaries.

One way to understand cross-domain faculty learning is to frame it as a dynamic community of practice. According to Wenger (1998), communities of practice are formed by people who engage in a process of collective learning in a shared domain. As such, "ways of doing things, ways of talking, beliefs, values, power relations-in short, practices-emerge in the course of this mutual endeavor. As a social construct, a community of practice is different from the traditional community, primarily because it is defined simultaneously by its membership and by the practice in which that membership engages" (Eckert \& McConnell-Ginet, 1992, p. 462). At $\mathrm{AC}$, layers of communities of practice emerge around individual courses, which serve as vehicles to allow a wide diversity of participants to engage in ongoing social practice, reflecting the value placed on ongoing negotiation among multiple perspectives. In collaboratively taught communities of practice, faculty need expertise in a particular content area ("know what"), experience putting their expertise into practice ("know how"), and a willingness to learn.

Lave and Wenger (1991) use an apprenticeship model to illustrate how individuals gain knowledge in communities of practice. They do not, however, sufficiently explain how experts from disparate fields play the simultaneous roles of expert, teacher, novice, learner, and, ultimately, knowledge integrator. Their apprenticeship model assumes a one-way, almost top-down approach to social learning. In a co-apprenticeship model, novices or newcomers are exposed over time to a social culture in which they gain skills, learn subtle ways of functioning, and sharpen their judgment through interactions and experiences guided by a mentor or group of co-mentors. Learning is therefore situated in the team's social interaction in a common situation in which all members have a stake. In the AC learning context, knowledge is practical, linked to action, and integral to the creation of meaning, and increased participation in communally experienced situations leads faculty to the interdependent outcomes of richer understanding and the construction of identity.

\section{Participants and Data Collection}

Data for this chapter were collected in part from a larger study that investigated how faculty learn outside the domain of their expertise in interdisciplinary learning communities (Young, 2003). As part of this study, ten experienced instructors of various backgrounds, disciplines, and faculty status self-selected to participate in two or three individual semistructured 
interviews using the same series of questions. Their responses shed light on how the participants reflect on learning or gain knowledge in a learning community.

Participants ranged in age from thirty-four to sixty-one and came from a variety of disciplines - one each from biology, cultural studies, philosophy, history, political science, psychology, and public policy, and three from English. They were diverse in faculty status (two doctoral students, three adjunct, two tenure-track, and three tenured faculty) and years of general teaching experience. Each participant had taught at least three years in learning communities, and some as many as ten years. The participants' individual ways of knowing, rooted in professional and personal experiences, were colored by disciplinary training but also shaped by collaborative experiences from across the university landscape.

\section{Cross-Domain Learning in the AC Community of Practice}

A requirement of learning community work is faculty collaboration. This collaboration is interdisciplinary and cross-domain, with participants who vary in age, experience, discipline, status level, theoretical outlook, and personal background. The common goal is the desire to collaborate intensely in order to improve undergraduate learning. AC faculty collaborate in teams of four to eight for the cohort-driven general education program, they pair up for interdisciplinary upper-level courses, and they work together outside class in intense planning meetings, shared governance activities, and active participation in student-centered issues and concerns. An inclusive faculty model underscores AC's commitment to broad-based expertise as librarians, student service professionals, instructional designers, graduate students, practitioners, and university administrators are invited to the table and into the fold.

Given the intense nature and the complex structure of interdisciplinary team-taught courses, it is impossible for individual AC faculty members to be conversant in all parts of an individual course, let alone contextualize the course within the larger integrated curriculum. Faculty also need to "create practice" in the soft areas of cross-domain faculty collaborative work, including how to contextualize and properly teach a particular concept from both one's own disciplinary perspective and the perspectives of their varied colleagues; divide and share complex tasks; work toward common goals; publicly address intellectual and interpersonal conflict; and collectively strive to improve the teaching process, approach to content, or interactions with students. In some of these areas, faculty have a deep level of experience in the "know how" of teaching in a cross-domain context; however, some faculty are beginners. 
Three examples illustrate how situating diverse faculty in complex courses sets the stage for cross-domain collaborative learning:

- A tenured biologist and a doctoral student in cultural studies collaborate to teach When Cultures Collide, an upper-level literature, film, and Web-based course that investigates cultural representations of change through music, art, food, folklore, tradition, and social habits.

- The former AC associate dean, an expert in political communication, and a librarian team-teach Presidential Primary 2004, an experiential learning course that challenges students to analyze the intersection of presidential candidacies, media coverage, and how technology has forged changes in the political process.

- A team of five teaches Community of Learners, the first in a suite of four eight-credit cohort-based general education courses for freshmen that conveys credits for composition, communication, and computer science. It is taught jointly by a tenured English professor, an experienced contract instructor with a background in Appalachian studies, a tenured community psychologist, and two graduate students with backgrounds in philosophy.

These courses reflect the diversity of faculty backgrounds, experience, and expertise in $\mathrm{AC}$ as "a full member of a community of practice requires access to a wide range of ongoing activity, old-timers, and other members of the community; and to information, resources, and opportunities for participation" (Lave \& Wenger, 1991, p. 100). Despite an impression of implied hierarchy within these courses, faculty collaborate on even footing because despite their external status, disciplinary background, or years of training, none can be expert in the entire course. For a course to work, collaboration is mandatory; for collaboration to work effectively, learning is required. In such a rich collaborative context, knowledge is socially constructed by communities of individuals, and meaning making is grounded in the context of relationships with others. Faculty are therefore motivated to think about thinking and reflect on their learning. They also become aware of, and attuned to, their colleagues' various ways of knowing. Acceptance of difference, coupled with a common appreciation for learning theory, helps faculty realize that new knowledge is ultimately a rich, continual process of give-and-take as reflected here by one instructor who conceptualizes her learning by stressing the importance of the team:

I'm not sure of precisely the kinds of ways [AC helps me think differently about my teachingl because I think of it more in terms of the 
team. I've learned more ways of how to talk about framing an issue in the class. I tap into the expertise of the team. I think the most dramatic learning lesson of working in the teams has to do with thinking about how different our epistemologies and cognitions are and those are obviously very intertwined.

Sustained collaboration across domains allows faculty to model concepts important to undergraduate learning: viewing problems from multiple perspectives, approaching and addressing difference, and engaging expert colleagues from diverse fields who offer themselves as learners, mentor each other, and, in the process, create new knowledge. In offering such an intellectually charged, integrative, and social learning environment, $\mathrm{AC}$ communicates high expectations of both faculty and students. The AC curricular model encourages faculty to learn to think like students again. As the college deemphasizes top-down communication of received knowledge from instructor to pupil, students are encouraged to be active participants in their learning by communicating and working with peers and faculty. Like faculty, students are given latitude and strong encouragement to make connections across boundaries, apply their learning in various contexts, and, by the very nature of nonclassroom learning, gain the perspective that comes from the primacy of real world experience.

\section{On Not Knowing: Faculty as Novice and Learner}

A cultural by-product of working in intense, collaborative work teams is that faculty learn the multiple, simultaneous roles of expert, teacher, learner, and novice. They do not simply take on these roles; they are constructed through interactions with peers as they learn to share expertise, pose new questions, and use storied examples to explain their perspective. They challenge colleagues' perceptions, negotiate conflict, and debate vigorously. In playing perhaps the trickiest role of all, that of novice, faculty trip, stumble, and shrug in frustration. Although it takes great courage to expose ignorance or admit confusion, novice thinking is quite useful in AC. The novices often question their partner (or the group) into rethinking fundamental assumptions about teaching and learning, as an AC instructor explains:

Novices are naive. I don't think it's a deliberate thing. You can't possibly be moving towards expertise on everything so it's just somebody who is naive who hasn't been exposed to something yet. A novice is good to a teaching team because they ask a lot of questions that require you to rethink your assumptions and be explicit about 
assumptions you're making. They also ask questions from a student perspective. Things they don't understand are things that students aren't going to understand, so they help you think about ways that you need to present material so that somebody hearing it for the first time can deal with it. They also get you to think. Sometimes there is new information that doesn't shake your world and then there are new ways of thinking about things that completely call into question values that you hold dear. They clue you in.

Playing multiple roles allows faculty to tap into other ways of knowing outside their field. These different ways of knowing serve as lenses that broaden each instructor's original area of expertise. Tapping into other ways of knowing can help one feel more confident as a newcomer. The curriculum, serving as a vehicle for learning, motivates faculty to share ideas and work together to solve the inevitable problems that arise in course design, teaching, or the facilitation of day-to-day activity. As faculty need to share "know how" in the successful creation and teaching of a $\mathrm{AC}$ course, they also need to learn how to appropriately share their "know what" in a way that is meaningful to lesser-knowing peers from other disciplines and widely divergent backgrounds. This intellectual stretching is not, however, an exercise in attempting to know all. Instead, it is an exercise in gaining perspective. Over time in AC, content experts move toward becoming context experts. Context experts are aware of their experiences enough to put those aside in order to be adaptable to the culture of the community:

Even if you're a four-year-old novice, you still have experiences to bring to the table. When I'm a novice at something and I'm trying to be a good novice, or when I'm trying to be good at approaching material for the first time, I try to be aware of my similar experiences. Somebody who's aware of his or her experiences and is willing to put those aside in an open fashion in a group dynamic is slightly different because you have other responsibilities, not just to yourself but to others. So a good novice to a learning community will perform the actions of a learning community, which is to be an active participant but then be adaptable to the culture of the community.

This does not mean that faculty specialization ceases to be important; rather, in lieu of each instructor teaching his or her own course or topic within the context of the team, faculty collaborate, depend on each other, and teach together. "Shared participation is the stage on which the old and new, the known and the unknown, the established and the hopeful, act out 
their differences and discover their commonalities, manifest their fear of one another, and come to terms for their need for one another" (Lave \& Wenger, 1991, p. 116). For a faculty member learning as nonexpert, it is important to have a flexibility to transfer and apply knowledge in multiple contexts. In short, they need to become conversant at integrating knowledge so as relate to students better. As one AC instructor reflects:

Well, the efficacy of the generalist is that person can relate to students better. You're not so buried in your discipline that you can't pay attention to the students. Don't get me wrong. I know tons of people who have incredible depth in their discipline and who are very attentive to students. But I think when we become obsessed by the discipline, we miss so many other opportunities, and part of that is learning around the periphery, around the edges, learning to contextualize things. And I don't know of a field that hasn't become more interdisciplinary. In a lot of ways we live in a time that demands academics to know more. We may not acknowledge it but I think about the broad learning.

In a cross-domain collaborative community of practice, faculty are both encouraged and enabled to know more than their specific area. They need to know the ways in which it is understood and how others might experience their subject. Despite the general willingness to learn that most faculty have, the experience they gain in their colleagues' areas of expertise tends to vary from course to course. Newcomers to AC tend to rely on stored knowledge that is comfortable for them to express; veteran AC faculty take more chances and are open to new mentorship opportunities. One faculty member feels that long-term exposure in an intense group culture results in knowledge rubbing off over time:

We [always] have newcomers but we never had anybody who's a complete novice. Newcomers tend to feel panicked, and feel like they actually are novices. A term that Anne Moore and Melinda Smith [pseudonyms] coined in talking about shared authority and collaboration is co-mentorship. It is so powerful. You may be the newcomer on the ream and you may be a graduate student and you may be a novice in the course and what it means to integrate knowledge. You may be a novice as a teacher! But all of a sudden in topic X, you are the expert on that topic. And it may be a conflict resolution graduate student and so there's something about group collaboration that's very obvious to that person [who will] have insight and knowledge that nobody else has.

The term co-mentorship underscores a breakdown in status and helps to bring equality to each of the roles that faculty members play. Faculty 
become helpers, freely willing to assist their peers. They also become accustomed to out-of-field learning, reinforcing the notion that they can become comfortable learning across boundaries. Sustained communication, interaction, and negotiation become increasingly important to faculty expertise:

There are all kinds of ways in which co-mentorship emerges in an integrative environment. I've yet to be on a team in which there wasn't real expertise demonstrated by somebody who would have been labeled a novice because of their relative inexperience in team work or in teaching in one of these courses. It's easier for me to think in terms of newcomers. We all remain novices to some extent, even veteran novices in certain areas, while we may gain expert status in some other areas. The co-mentorship thing is absolutely crucial to understanding what happens with these teams. And how that role reverses and reverses and reverses.

As AC faculty play myriad interdependent, overlapping, and shifting roles, they take on the key role of veteran novice. Faculty challenge each other, learn to ask basic questions, and demonstrate role flexibility. However, they do not become complacent in their role as novice; as the curriculum adapts and as student expectations and needs evolve, faculty become more practiced in the functioning of a collaborative learning culture that they as a group helped form.

\section{Deep Experts and the Evolving Learning Conversation}

One original goal of $\mathrm{AC}$ was to become a teaching incubator where disciplinary-based faculty would leave their department and join AC "on loan" for a semester or two. Communities of practice do not work for everyone, however. Some faculty returned to their department cynical about group work. Innovation did not diffuse, and the multiplier effect was blunted at the learning community doors. AC has also had talented faculty who resist the community of practice as passive observers, polarizers, or dominators. They are unable to adapt to the intellectual subtleties of knowledge integration. When certain faculty do not fit in, their resistance can sometimes add punch to a team in need of a spark of dissension-or the outlier faculty member can be a nuisance:

Well, I don't do social contact. I have for years drawn a very strong boundary and it has to be solely with personal preferences. I like all the people. I enjoy collaborating with them professionally. But I find the AC system is too rigid. That things had to be negotiated and it had to be consensus of all seven people. Frankly I thought that was 
bullshit. I understand the arguments about equity and I think they're nonsense. I find it extremely difficult to talk to people who just want to sit around all day and fondle something. You come up with a proposed reading and you spend three hours discussing it and you think you have a consensus and you get back and somebody sent an e-mail saying, "I found another reading." It just drove me nuts.

Deep experts are indispensable to learning communities; however, deep experts who are overly rooted in a particular domain struggle as they tend to be unpracticed at framing what they know in the context of other experts from other fields. They are unable to relate what they know in a manner that is knowable or learnable to a broadly educated audience of faculty peers. The following is an example from a faculty member with a background in cultural studies who collaborated with a biologist to teach When Cultures Collide:

When I first taught When Cultures Collide, both of us were in the classroom together. We were friends before that, so we really had a sense for each other as people. We really had a high regard for each other, and that made it a lot easier. But it was still hard on some levels. You model conflict. You learn that your way isn't always necessarily right. You're forced into working out differences of opinion. My colleague would say something and I'd think, "God that's such a scientific point of view." So you have to figure out how to introduce your perspective without undercutting the other instructor whose point of view is just as valid.

Unless faculty are able to share what they know or express interest in learning from experts in other fields, their role in cross-domain collaboration will be diminished. Similarly, faculty who lack either expertise or a social context by which to communicate with peers from diverse knowledge areas, share existing knowledge, or gain new knowledge are ultimately less effective in helping students integrate their knowledge. Unless faculty have learned to embrace integration, it will be difficult for them to teach in a highly integrated fashion. Faculty need a community of peers in order to learn how to integrate knowledge from many fields. To be an integrator of diverse knowledge fields requires being an adept builder of bridges, and these bridges must be sturdy enough to cross diverse intellectual, interpersonal, and practical terrain yet flexible enough to support questioning, negotiation, and openness required of integrative learning:

In terms of disciplinary background or fields of inquiry, I think lots of different people could teach well in Anonymous College as long as 
they weren't completely wedded to one disciplinary perspective. I think you need to have people who understand that knowledge is constructed, the multiple perspectives, that multiple ways of knowing are valid and certain people are unable to do that.

Knowledge integration, often elusive and difficult to achieve, is " $m a k$ ing connections across disciplines" by "placing them in a larger context" (Boyer, 1990, pp. 18-19). It requires faculty to take great professional and personal risk as they regularly place themselves in uncomfortable positions of learning outside their original area of expertise. Knowledge integration is an outcome of faculty playing multiple simultaneous roles in the context of a rich cross-domain community of practice. Ironically it is optimally achieved when confidence, certainty, and intellectual heft are combined with the uncertainty, ambiguity, or confusion that comes with being a novice or learner.

\section{Implications for Faculty Identity}

Faculty who teach individual courses have responsibilities to students, their department, and the broader curriculum; cross-domain collaborative faculty also have responsibilities to one another. This mutual responsibility helps both reinforce and embolden the AC community of practice in which faculty embrace more robust conceptions of expertise with important implications for faculty identity. This new expertise is rooted in community that pushes faculty beyond the limitations of decontextualized deep knowledge. As faculty are better able to frame problems in their own area, they are also better equipped to communicate across disciplinary languages, and they become better and more knowledgeable instructors both inside and outside the AC community. As they gain knowledge and learn about others, they also learn about themselves, while gaining an improved tolerance for ambiguity and a better understanding of local and broader surroundings. The cross-domain collaborative learner has a rhetorical awareness that allows him or her to communicate complex ideas to a wide array of audiences in a wide variety of contexts. It is, in part, rhetorical awareness that helps faculty form rich communities of practice, freely share what they know, learn outside the domain of their expertise, and co-create knowledge.

For integrated undergraduate learning community programs like AC to flourish, faculty need the organizational latitude to collaborate across boundaries. To do so, they need to be rewarded for demonstrating how being exposed to other areas of inquiry can improve their own practice. In the fifteen years since the college's inception, one of the more pleasant 
surprises at $\mathrm{AC}$ has been how senior faculty have learned from graduate students or faculty at the beginning of their careers. This is due in large part to the generosity of more experienced faculty who are willing mentors and are open to being mentored by a junior faculty member or graduate student. In the end, faculty acculturated in this rich community-of-practice process and philosophy pass on the cultural baton to learning community students as well as the next generation of learning community faculty.

\section{REFERENCES}

Becher, T., \& Trowler, P. (2001). Academic tribes and territories: Intellectual enquiry and the culture of disciplines (2nd ed.). London: Open University Press.

Berthoin Antal, A., Lenhardt, U., \& Rosenbrock, R. (2001). Barriers to organizational learning. In M. Dierkes, A. Berthoin Antal, J. Child, \& I. Nonaka (Eds.), Handbook of organizational learning and knowledge (pp. 865-885). New York: Oxford University Press.

Boyer, E. L. (1990). Scholarship reconsidered: Priorities of the professoriate. Princeton, NJ: Carnegie Foundation for the Advancement of Teaching.

Cox, M. D. (2004). Introduction to faculty learning communities. In M. D. Cox \& L. Richlin (Eds.), New directions for teaching and learning: No. 97. Building faculty learning communities (pp. 5-23). San Francisco: Jossey-Bass.

Creamer, E. G. (2005). Insight from multiple disciplinary angles: A case study of an interdisciplinary research team. In E. G. Creamer \& L. R. Lattuca (Eds.), New directions for teaching and learning: No. 102. Advancing faculty learning through interdisciplinary collaboration (pp. 37-44). San Francisco: Jossey-Bass.

Davenport, T. H., \& Prusak, L. (1998). Working knowledge: How organizations manage what they know. Boston: Harvard Business School Press.

Dixon, N. M. (2000). Common knowledge: How companies thrive by sharing what they know. Boston: Harvard Business School Press.

Eckert, P., \& McConnell-Ginet, S. (1992). Think practically and look locally: Language and gender as community-based practice. Annual Review of Anthropology, 21, 461-490.

Lave, J., \& Wenger, E. C. (1991). Situated learning: Legitimate peripheral participation. Cambridge: Cambridge University Press.

Nonaka, I. (2008). The knowledge creating company. Boston: Harvard Business School Press.

Smith, B. L., Macgregor, J., Matthews, R., \& Gabelnick, F. (2004). Learning communities: Reforming undergraduate education. San Francisco: Jossey Bass.

Tagg, J. (2003). The learning paradigm college. San Francisco: Jossey-Bass/Anker. 
Tierney, W. G. (2008). The impact of culture on organizational decision making: Theory and practice in higher education. Sterling, VA: Stylus.

Wenger, E. C. (1998). Communities of practice: Learning, meaning, and identity. New York: Cambridge University Press.

Wenger, E. C., McDermott, R., \& Snyder, W. M. (2002). Cultivating communities of practice. Boston: Harvard Business School Press.

Young, J. B. (2003). How experts learn outside the domain of their expertise: An exploration of a faculty community of practice. Fairfax, VA: George Mason University. 